\title{
PLANT LAYOUT OPTIMIZATION OF OVEN MANUFACTURING UNIT USING CORELAP ALGORITHM
}

\author{
M. Rajesh ${ }^{1}$, N V R Naidu ${ }^{2}$, P. Naveen Kumar ${ }^{3}$ \\ ${ }^{1}$ Assistant Professor, Department of IEM, MSRIT, Bengaluru \\ ${ }^{2}$ Professor \& Principal, MSRIT, Bengaluru \\ ${ }^{3} P G$ Student, Department of IEM, MSRIT, Bengaluru
}

\begin{abstract}
The objective of this paper to optimize the existing plant layout of a company that manufactures ovens. The existing layout is redesigned to reduce the cost and effort of material handling. The initial layout of the company had $43.20 \%$ surplus area and it was incurring a total material handling cost of Rs. 2588.2/month. Facilities planning and design techniques were used to obtain an optimal layout. Use of CORELAP algorithm reduced surplus area of the layout to $8.83 \%$.
\end{abstract}

Keywords: Facility planning and design, Computerized Relationship Layout Planning (CORELAP).

\section{INTRODUCTION}

The layout determines the way in which materials flow through the operation. Small changes in the position of a machine in a factory can affect the flow of materials considerably. This in turn can affect the costs and effectiveness of the overall manufacturing operation. Most of the layouts are designed for the initial conditions of the manufacturing facility, as the company grows to adapt internal and external changes, a re-designing of layout is necessary. The reasons for re-designed layout is based on the inter relationship between different departments in the product floor. In this paper an attempt is made to modify the existing layout of a industry in order to solve the existing problems related to the material movement in the company.

\section{LITERATURE REVIEW}

The facilities of an industry are crucial as they usually represent the largest and the most expensive assets of an organization. Layout design has been considered as one of the vital areas where business performance improvement can be realized. Facilities are of crucial importance to organizations since they usually represent the largest and most expensive assets of an organization.

Effective placement of the facilities is known to have a significant impact upon manufacturing costs, work in process, lead times and productivity. A good placement of facilities contributes to the overall efficiency of operations and can reduce up to $50 \%$ of the total operating expenses. It's main concern is reducing cost by maximizing adjacency of highly interacting components of a system or reducing material handling cost or distance between work stations. If facilities are arranged optimally, manufacturers can decrease work in process, material handling costs, total production costs and significantly enhance their system's efficiency.
The computerized layout methods, either construction or improvement-type routines are heuristics. Construction-type layout routine generates a block layout based on the relationship between different departments. Commonly used is Computerized Relationship Layout Planning (CORELAP). Improvement-type routines require an input of a feasible block layout and aim to reduce internal transport cost by attempting simultaneous pair-wise position exchanging among the departments. The most popular improvementtype method is Computerized Relative Allocation of Facilities Technique (CRAFT). This paper adapts CORELAP algorithm to finalize a best possible layout.

\section{DATA COLLECTION}

The factory has two sections namely oven manufacturing and bread manufacturing departments. The area of each department, distance between departments, relationship between departments, etc. were collected. Brain storming was done at the factory to derive the relationship between different departments. The relationships of departments is recorded in the in Figure 1

\section{LAYOUT MODIFICATION USING CORELAP}

CORELAP constructs a layout for a facility by calculating the total closeness rating (TCR) for each department. TCR is the sum of the numerical values assigned to the closeness relationships ( $\mathrm{A}=6, \mathrm{E}=5, \mathrm{I}=4, \mathrm{O}=3, \mathrm{U}=2, \mathrm{X}=1$ ) where, A- Absolutely essential, E- Essential, I- Important, OOrdinary Closeness, U- Unimportant and X- extremely undesirable between departments. Total Closeness Rating is calculated using the data available in ARC. The calculated TCR is tabulated is Table 1 shown below. 


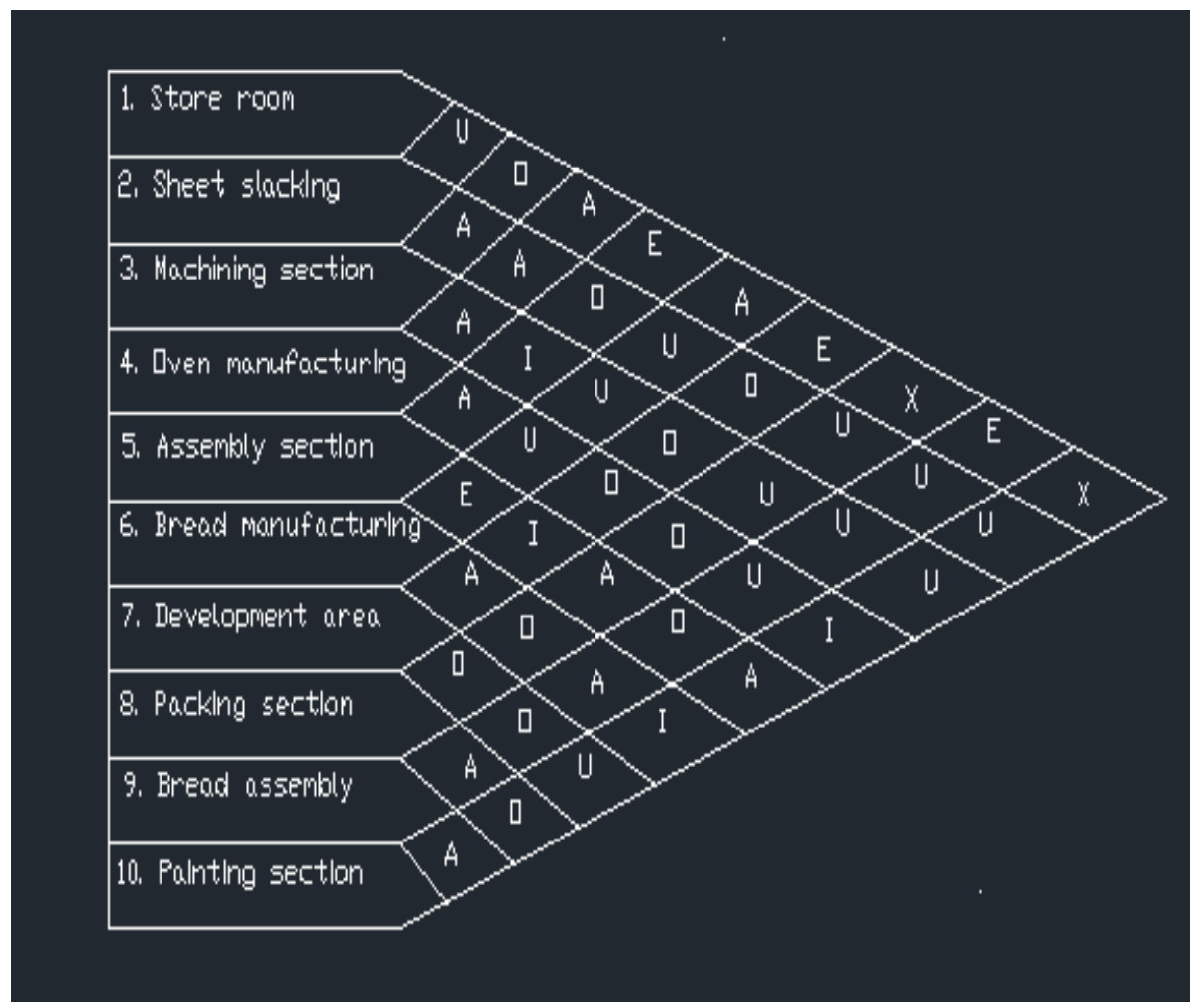

Fig 1: Activity Relationship Diagram

Table 1: Total Closeness Rating calculation

Values
\begin{tabular}{|l|l|l|l|l|l|l|l|l|l|l|l|l|l|l|l|l|l|l|}
\hline- & 1 & 2 & 3 & 4 & 5 & 6 & 7 & 8 & 9 & 10 & A & E & I & O & U & X & \\
\hline 1 & - & U & O & A & E & A & E & X & E & X & 2 & 3 & 0 & 1 & 1 & 2 & 34 \\
\hline 2 & U & - & A & A & O & U & O & U & U & U & 2 & 0 & 0 & 2 & 5 & 0 & 28 \\
\hline 3 & O & A & - & A & I & U & O & U & U & U & 2 & 0 & 1 & 2 & 4 & 0 & 30 \\
\hline 4 & A & A & A & - & A & U & O & O & U & I & 4 & 0 & 1 & 2 & 2 & 0 & 38 \\
\hline 5 & E & O & I & A & - & E & I & A & O & A & 3 & 2 & 2 & 2 & 0 & 0 & 42 \\
\hline 6 & A & U & U & U & E & - & I & A & O & A & 3 & 1 & 1 & 1 & 3 & 0 & 36 \\
\hline 7 & E & O & O & O & I & I & - & O & O & U & 1 & 1 & 1 & 5 & 1 & 0 & 32 \\
\hline 8 & X & U & O & O & A & A & O & - & A & O & 2 & 0 & 0 & 4 & 2 & 1 & 29 \\
\hline 9 & E & U & U & U & O & O & O & A & - & A & 3 & 1 & 0 & 2 & 3 & 0 & 35 \\
\hline 10 & X & U & U & A & A & A & U & O & A & - & 2 & 0 & 2 & 1 & 3 & 1 & 30 \\
\hline
\end{tabular}

\section{Determination of the sequence of departments}

The department having highest TCR is selected as the first department in the sequence. Next, the relationship chart is scanned for an "A" relationship the department has with other departments. If an ' $A$ ' exists, that department is selected as the next to enter the sequence, if there are two or more departments have the same relationship with the selected department, then the department having the highest TCR is selected; if a tie still exists, the department having the largest area is selected.

If no unassigned departments exists that as an " $A$ " relationship with the second department, the procedure is repeated considering "E" relationships, then "I" relationships, and so on.
From Table 1, department 5 has highest TCR (42) and is selected as the first department in the sequence.

Now ARC (Figure 1) is scanned to check for relationship " $A$ " the department 5 has with other departments. It was noticed that departments 4,8 and 10 having " $A$ " relationship (i.e. a tie exists).

Hence, the department having highest TCR (department 4 having TCR as 38) was selected as the next department to enter the sequence.

Now, scanning department 4 for " $A$ " relationship The department 1, 2, 3 and 5 have " $A$ " relationship, department 1 was selected as it has the highest TCR of 34 .

Now, scanning department 1 for " $\mathrm{A}$ " relationship 
The department 4 and 6 has " $A$ " relationship, it was noticed that department 4 already exists in the sequence. Hence, department was 6 chosen.

Likewise all the 10 departments were bought into the sequence.

\section{Construction of layout}

The layout was constructed by selecting a suitable scale (grids) based on the area of the department. Then, locating the first department (5) in the sequence at the center and other around it depending on the relationships in order to achieve a highest layout score. For convenience, the total area of all the 10 departments was computed and was divided by 2 to get the midpoint area. Departments having area less than midpoint was assigned with one grid and more than midpoint as two grids. The layout score was determined using the relationship weights as listed below.

$$
\begin{array}{ll}
A=243 & O=9 \\
E=81 & U=3 \\
I=27 & X=0
\end{array}
$$

Sample placement ranking score calculation for alternative layout 4
A: $10 \times 243=2430$
$\mathrm{E}: 1 \times 81=81$
I: $1 \times 27=27$
O: $1 \times 9=9$
$\mathrm{U}: 1 \times 1=1$
$\mathrm{X}: 0 \times 0=0$
Total layout score $=2548$

Table 3 provides the different combination of layout placements

1

\begin{tabular}{|c|c|c|c|c|c|}
\hline 2 & 3 & 8 & & & \\
\hline 4 & 4 & 5 & 10 & 10 & 9 \\
\hline 1 & 1 & & & & \\
\hline 6 & 7 & & & & \\
\hline
\end{tabular}

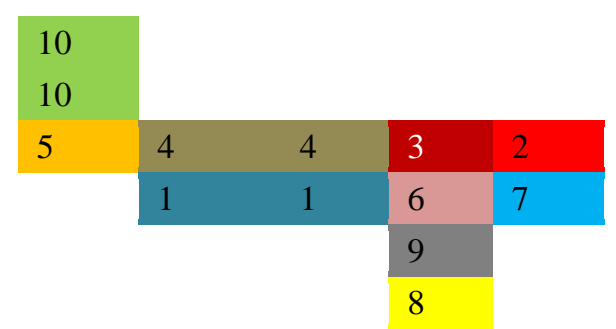

Layout score $1=1747$

3

Layout score $3=1821$

5

Layout score $5=2296$

7

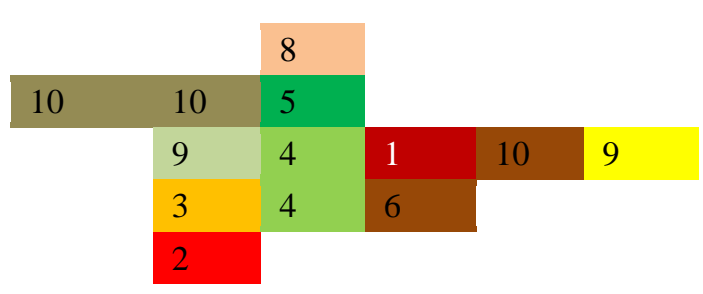

2

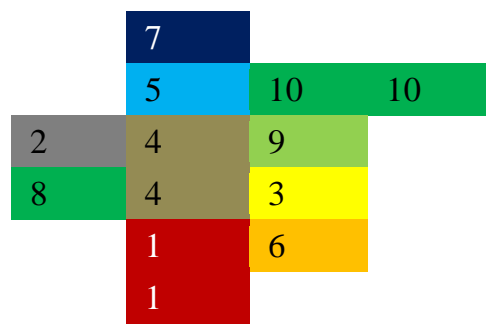

Layout score $2=1741$

4

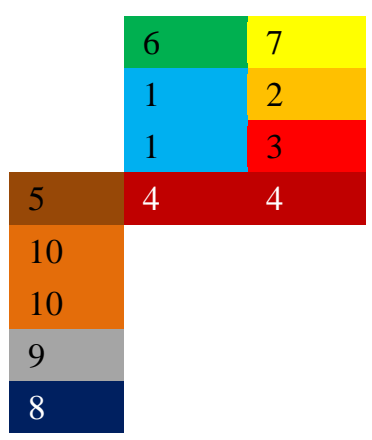

Layout score $4=1990$

6

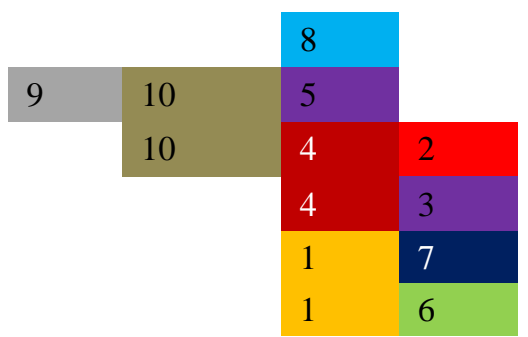

Layout score $6=2547$
8 


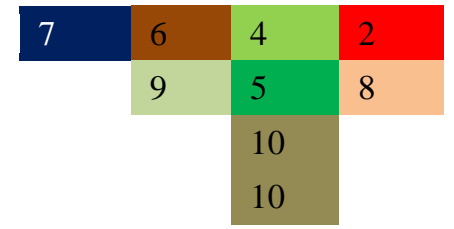

Layout score $7=2288$

9

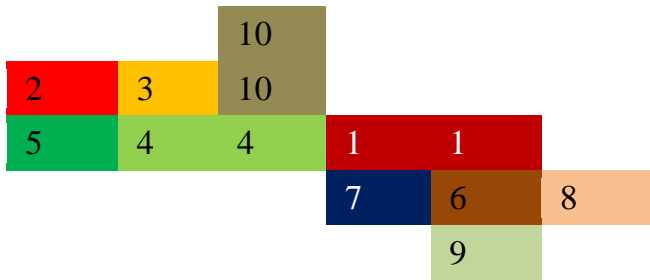

Layout score $9=1828$

11

\begin{tabular}{|l|l|l|}
\hline 5 & 10 & 10 \\
\hline 4 & 3 & 2 \\
4 & 1 & 1 \\
\hline & 6 & 7 \\
\hline & 9 & \\
& 8 & \\
& &
\end{tabular}

Layout score $11=1830$

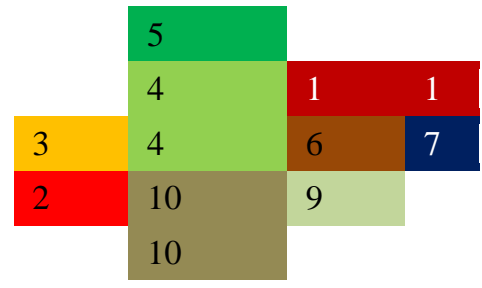

Layout score $8=1847$

10

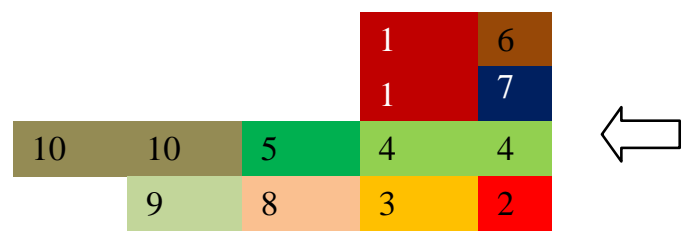

Layout score $10=2548$

12

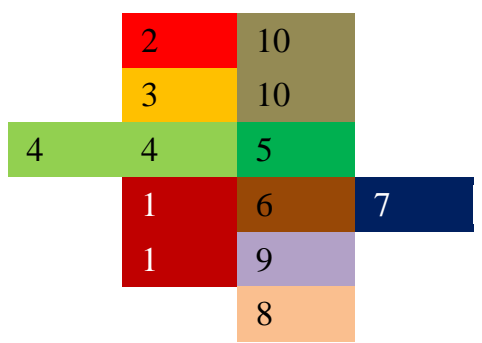

Layout score $12=1901$

Fig 2: Alternative combination of layout

Alternative layout 10 was selected as the best layout. The surplus area calculated was $43.20 \%$ as shown in Figure 3.

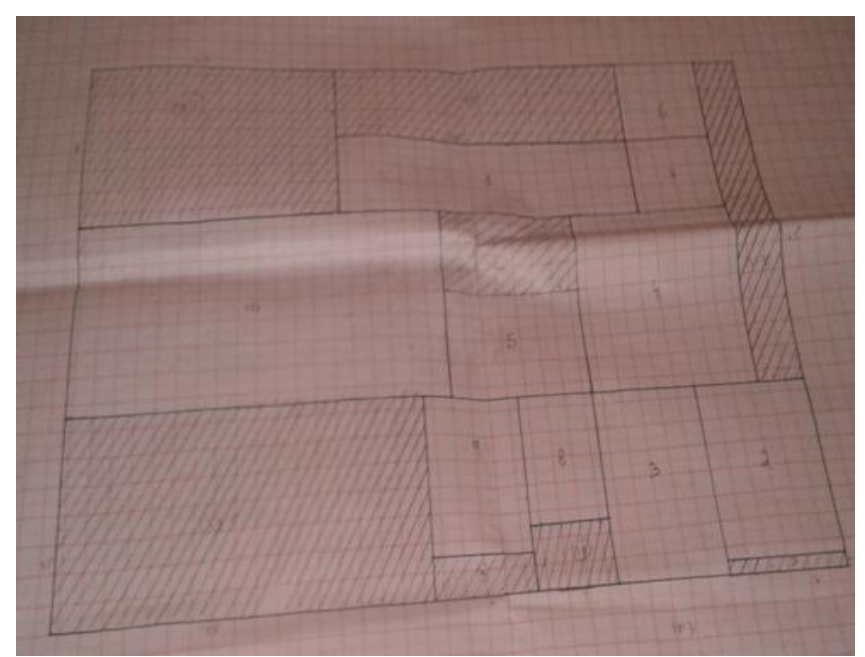

Fig 3: Best alternative layout score for 10 Departments

The surplus area was calculated as shown below

Surplus area $=$ The empty area of each department $/$ Total area $* 100$

$=68+109.6+133.5+9+10+3+31.25+24.5 / 900.05 *$

100

$=43.20 \%$
In order to determine and eliminate the excess area in the proposed layout, template method was adopted. Here department templates were swapped until the surplus area was as less as possible. This is shown in Figure 4, 5 and 6.

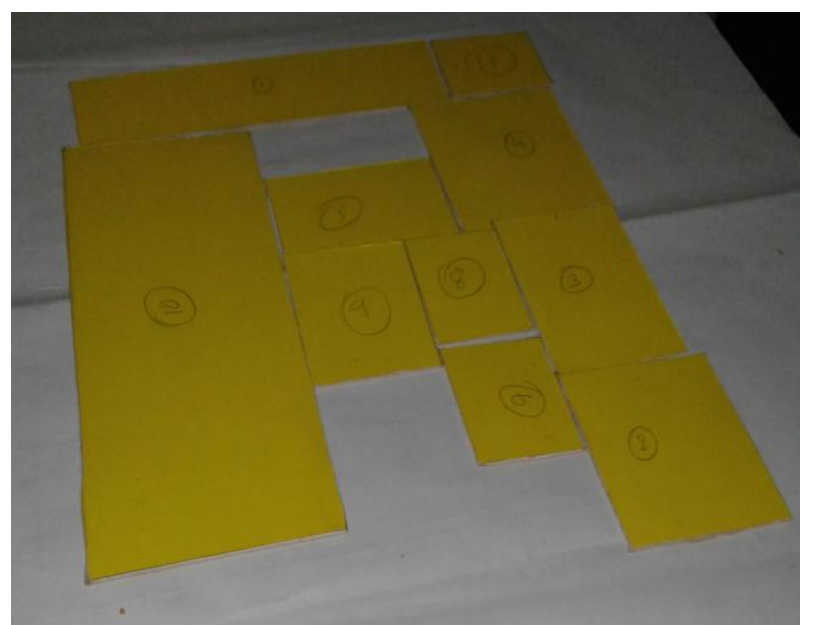

Fig 4: proposed layout 1 using template for 10 Departments 


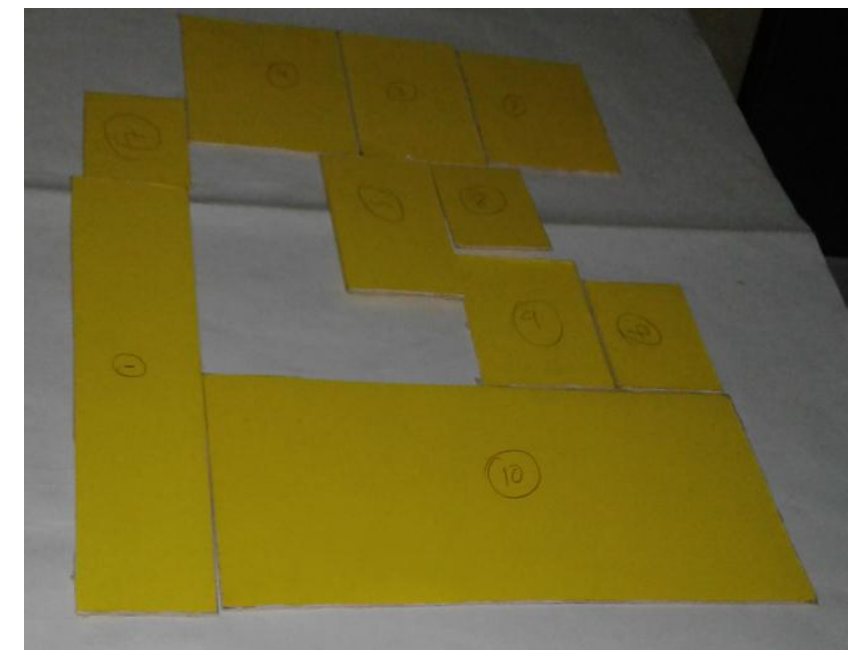

Fig 5: proposed layout 2 using template for 10 Departments

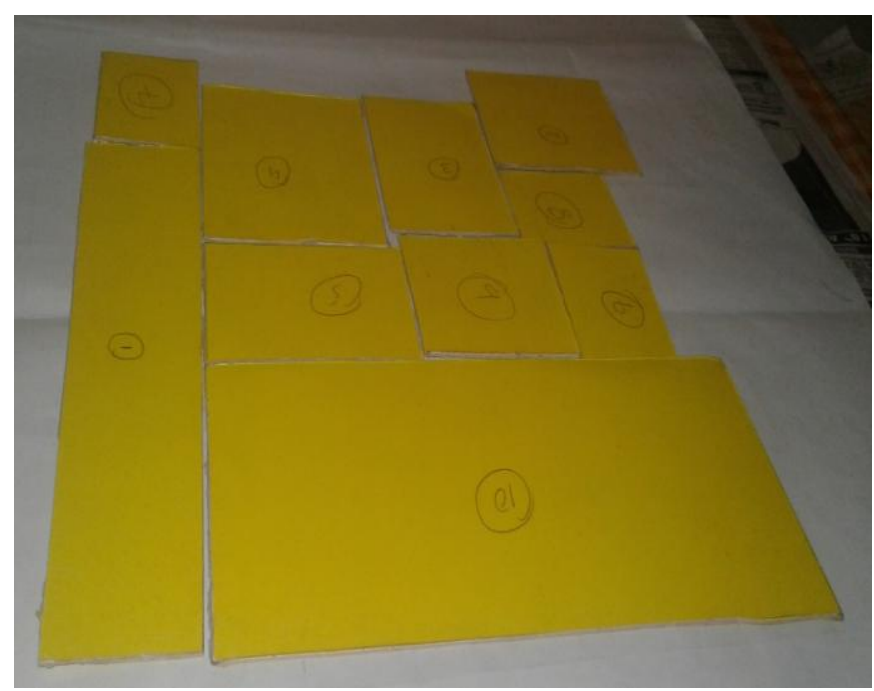

Fig 6: proposed layout 3 using template for 10 Departments

The layout is redesigning in order to calculate the \% surplus area. It noticed that from the prepared redesign layout, The layout score was 2548 and the \% surplus area is $8.83 \%$ as shown in figure 7 .

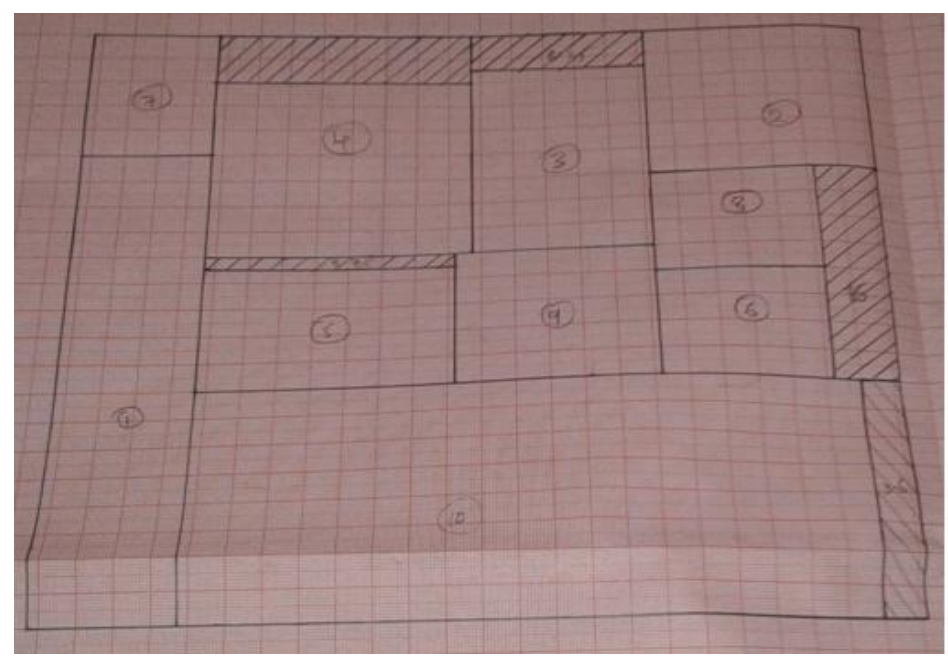

Fig 7: CORELAP algorithm proposed layout for 10 Departments
The surplus area is calculated as shown in below

Surplus area $=$ The empty area of each department $/$ Total

$$
\begin{gathered}
\quad \text { area } * 100 \\
=8.25+16+3.6+3.75+16 / 539 * 100=8.83 \%
\end{gathered}
$$

The layout is redesigning in order to calculate the \% surplus area. It was noticed that for the prepared redesign layout the $\%$ surplus area as $8.83 \%$ and is selected as the best layout for the factory.

\section{CONCLUSION}

It was found that the company had $43.20 \%$ surplus area. Modification of the existing plant layout of a factory was obtained using CORELAP algorithm, which resulted in minimizing the total surplus area to $8.83 \%$.

\section{REFERENCES}

[1] Gopalakrishnan, R, Turuvekere, D.P. Gupta, "Computer Integrated Facilities Planning and Design”, Facilities, Vol. 22, year 2004.

[2] Ornurai Sangsawang and Sunarian Chanta, "Human vs. computer Algorithms for the plant layout problem" published on June 1, 1980, page no: 570574.

[3] Ameha Mulugeta, Birhanu Beshah and Daniel Kitaw "A Construction algorithm for area placement evaluation", published on 22 Oct 2007, page no: 1283-1295.

[4] Proceedings of the International conference on computer and Industrial management, ICIM, 2005.

[5] Computerized Facilities Layout Design, Journal of EEA, Vol. 30, 2013. 